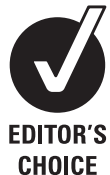

CHOICE
- An additional appendix is published online only. To view this file please visit the journa online (http://pmi.bmi.com).

${ }^{1}$ Centre for Medication Safety and Service Quality, Imperial College Healthcare NHS Trust and The School of Pharmacy, University of London, London, UK

${ }^{2}$ Pharmacy Department, Charing Cross Hospital, London, UK ${ }^{3}$ Department of Practice and Policy, The School of Pharmacy, University of London, London, UK

${ }^{4}$ Centre for Patient Safety and Service Quality, Imperial College London, London, UK ${ }^{5}$ Division of Surgery and Cancer, Department of Surgery, St Mary's Campus, Norfolk Place, London, UK

\section{Correspondence to} Bryony Dean Franklin, Pharmacy Department, Ground Floor, Charing Cross Hospital, Fulham Palace Road, London W6 8RF UK; bryony.deanfranklin@ imperial.nhs.uk

Some preliminary results of this work were presented as two conference abstracts: Franklin BD. A multi-centre study of prescribing errors in hospital inpatients. Abstract Presented at the Patient Safety Congress. Birmingham. 25-26 May 2010. Franklin BD, Reynolds M. A comparative study of prescribing errors in three NHS organisations. Abstract

Presented at Royal

Pharmaceutical Society Conference. London. 5-6 September 2010 .

Received 19 January 2011 Accepted 10 June 2011 Published Online First 14 July 2011

\title{
Prescribing errors in hospital inpatients: a three-centre study of their prevalence, types and causes
}

\author{
Bryony Dean Franklin, ${ }^{1,2}$ Matthew Reynolds, ${ }^{1,2}$ Nada Atef Shebl, ${ }^{3}$ Susan Burnett, ${ }^{4,5}$ \\ Ann Jacklin ${ }^{1,2}$
}

\section{ABSTRACT}

Aim To compare the prevalence and causes of prescribing errors in newly written medication orders and how quickly they were rectified, in three NHS organisations. Methods Errors in newly written inpatient and discharge medication orders were recorded in Spring/Summer 2009 by ward pharmacists on medical admissions and surgical wards, as well as the number of erroneous doses administered (or omitted) before errors were corrected. Logistic regression analysis was used to explore the effects of ward (nested within organisation) and clinical specialty, and whether the pharmacist had checked the patient's medication history during data collection. Causes were explored using semistructured interviews with key informants.

Results Overall, 1025 prescribing errors were identified in 974 of 6605 medication orders $(14.7 \%, 95 \%$ confidence interval (CI) $13.8 \%$ to $15.6 \%$ ). A mean of 0.9 doses were administered (or omitted) before each error was corrected (range 0-11), with differences between specialties and organisations. The error rate on medical admissions wards $(16.3 \%)$ was significantly higher than that on surgical wards (12.2\%), but this was accounted for by the higher proportion of prescribing being on admission, where omission of patients' usual medication was often identified. There were significant differences among wards (and organisations). Contributing factors included lack of feedback on errors, poor documentation and communication of prescribing decisions, and lack of information about patients' medication histories from primary care.

Conclusions There were variations among wards, organisations and specialties in error rates and how quickly they were rectified. Exploring reasons for differences between organisations may be useful in identifying best practice and potential solutions.

\section{INTRODUCTION}

Prescribing errors are common, with errors reported in up to $9 \%$ of inpatient medication orders in the UK. ${ }^{1}$ A median error rate of $7 \%$ was reported in a recent international systematic review of handwritten inpatient prescribing. ${ }^{2}$ About $1-2 \%$ of inpatients are harmed by medication errors, the majority of which relate to prescribing. ${ }^{3} 4$ Even errors that do not result in harm create additional work and can adversely affect patients' confidence in their care.

Wide variation in methods and definitions means it is virtually impossible to compare different studies, ${ }^{5-8}$ making it difficult to draw conclusions about similarities or differences in prescribing error rates between wards, specialties or organisations. The only UK study to present comparative data for more than one organisation is in paediatrics. ${ }^{9}$ Identifying differences between organisations would help us understand best practice and make recommendations for error prevention.

Previous studies have focused on counting and classifying errors; none have collected data on how quickly errors are identified and rectified, which may be useful as an indicator of the system's resilience to error. A system where errors are quickly rectified is likely to be safer than one where they are not.

Our objectives were (1) to compare the prevalence, types and clinical importance of prescribing errors and how quickly they were rectified in at least two wards in each of three NHS organisations; (2) to identify common themes in relation to their causes; (3) to make recommendations for error prevention

\section{METHODS \\ Design}

A prospective study of prescribing errors identified by ward pharmacists, followed by a series of interviews to explore their causes. Data collection took place in May, June and July 2009.

\section{Setting}

We studied at least one medical admissions ward and at least one surgical ward in each of three organisations; the characteristics of each hospital and ward are presented in table 1. These specialties were chosen to represent different types of wards, while being represented in all three organisations Medical admissions wards have rapid patient turnover, with unplanned admissions and many patients on multiple long-term medications. General surgical wards typically have a wider range of lengths of stay, with mixed emergency and elective admissions, and a focus on short-term medication such as analgesics and antibiotics.

\section{Definitions}

A medication order is one drug prescribed for a patient; there are usually multiple medication orders on each patient's inpatient drug chart and on each discharge prescription.

We used a practitioner-led definition of a prescribing error, ${ }^{11}$ extensively used by others (box 1). ${ }^{2} 1213$ We also recorded whether or not 
Table 1 Characteristics of hospitals and wards studied

\begin{tabular}{|c|c|c|c|}
\hline Organisation & A & B & C \\
\hline Hospital type & Teaching & Non-teaching & Teaching \\
\hline Beds & 1590 & 259 & 911 \\
\hline Inpatient prescribing & Typical UK paper drug chart ${ }^{10}$ & $\begin{array}{l}\text { Typical UK paper drug chart but with } \\
\text { no section to indicate the maximum } \\
\text { dose of drugs given 'when required' }\end{array}$ & $\begin{array}{l}\text { Typical UK paper charts but with } \\
\text { pre-printed units }(\mathrm{g} / \mathrm{mg} / \mu \mathrm{g}) \text { in the } \\
\text { dose sections }\end{array}$ \\
\hline Discharge prescribing & Almost all computerised & Some computerised and some paper based & $\begin{array}{l}\text { Some computerised and some } \\
\text { paper based }\end{array}$ \\
\hline \multicolumn{4}{|l|}{ Medical admissions wards } \\
\hline Wards & 4 wards ( 69 beds in total) & 1 ward (24 beds) & 1 ward (33 beds) \\
\hline Pharmacist availability & $11 \mathrm{~h}$ weekdays, $5.5 \mathrm{~h}$ weekends & $3 \mathrm{~h}$ weekdays, none at weekends & $2 \mathrm{~h}$ weekdays, none at weekends \\
\hline on ward & Post-take rounds attended & Post-take rounds attended & Post-take rounds attended \\
\hline \multicolumn{4}{|l|}{ Surgical wards } \\
\hline Wards & 1 vascular surgery ( 28 beds) & 2 general surgical wards (33 beds in total) & 1 orthopaedic surgery (26 beds) \\
\hline $\begin{array}{l}\text { Pharmacist availability } \\
\text { on ward }\end{array}$ & $\begin{array}{l}\text { Visit from pharmacist each weekday } \\
\text { and short visit on Saturdays }\end{array}$ & Visit from pharmacist each weekday & Visit from pharmacist each weekday \\
\hline
\end{tabular}

errors resulted in interventions, defined as speaking with another non-pharmacy member of the healthcare team or writing in the patient's health records. ${ }^{14}$

\section{Prevalence, types and clinical importance of prescribing errors in each organisation and how quickly they were rectified Data collection}

Data were collected by ward pharmacists for a 2 -week period on each study ward, using established methods. ${ }^{15}$ With an estimated 250 medication orders written each week on a typical ward, 2 weeks' data allowed identification of an erroneous order rate of $7 \%^{2}$ with $95 \%$ CI $4.8 \%$ to $9.2 \%$. Pharmacists recorded the number of newly written regular, 'when required' and discharge medication orders screened each weekday, together with whether or not they had also checked the patient's medication history on that particular day. Medication prescribed to be given 'once only' and continuous intravenous infusions were excluded. Errors identified at the same time as medication history taking include errors in ascertaining and prescribing patients' usual long-term medication on admission to hospital, as well as any other errors identified on that day. Pharmacists documented details of any prescribing errors identified, the number of doses administered (or omitted) before the error was corrected, whether or not they made an intervention to correct the error and the number of occupied beds on the ward. Each medication order could be associated with more than one error. Each individual prescribing error was classified into 1 of 13 mutually exclusive categories.

\section{Analysis}

The denominator for calculating the error rate was the number of newly written regular, 'when required' and discharge medication orders screened by ward pharmacists, plus any medication orders omitted. ${ }^{16}$ We calculated the prevalence of

\section{Box 1 Definition of a prescribing error ${ }^{11}$}

A clinically meaningful prescribing error occurs when, as a result of a prescribing decision or prescription-writing process, there is an unintentional, significant reduction in the probability of treatment being timely and effective, or increase in the risk of harm when compared with generally accepted practice. This definition is accompanied by lists of situations that should be included and excluded as prescribing errors. erroneous orders for each ward and organisation and estimated the error rate per 100 patient days.

\section{Comparison between specialties, wards and organisations}

To explore variation between organisations, specialties and wards and whether or not the patient's medication history was checked on the day of data collection, we performed separate analyses for each of these variables and then conducted logistic regression analyses using SPSS v 17.0. We first explored the effect of specialty and whether or not a medication history was checked for that patient on that day. A second multi-level model then explored the effect of ward (level 1), nested within organisation (level 2), together with whether or not a drug history was checked for that patient on that day. All were categorical variables.

\section{Clinical importance}

Five experienced healthcare professionals (three pharmacists, a doctor and a nurse) assessed the potential clinical importance of a random sample of one in five errors from each ward, using a validated method ${ }^{17} 18$ on a scale of 0 (no clinical consequences) to 10 (would result in death). The mean score for each error was used as an index of clinical importance; a score of 7.0 or more indicates a serious error. ${ }^{17}$

\section{Exploring the causes of prescribing errors}

\section{Data collection}

We conducted semistructured interviews with a convenience sample of prescribers, pharmacists and nurses from the clinical areas concerned. ${ }^{19} 20$ These professions were chosen to reflect those most involved with writing, or interpreting, prescriptions. We selected some typical prescribing errors that had been identified on each ward during the prevalence study and used these as prompts to explore their likely causes. Interviews were conducted by a research psychologist, recorded using a digital sound recorder and took about 20-30 min. The interview schedule is given in the online supplementary appendix 1.

\section{Analysis}

A coding frame was constructed, based on a framework for analysing risk and safety in clinical medicine, ${ }^{21}$ to explore factors contributing to error and the associated defences. All coding was checked by a second researcher with any differences resolved via discussion. Quotes were selected to illustrate the key themes.

The study had ethics approval (Hammersmith and Queen Charlotte's \& Chelsea Research Ethics Committee, reference number 09/H0707/27). Staff gave written informed consent for interviews 


\section{RESULTS}

Prevalence, types and clinical importance of prescribing errors and how quickly they were rectified

Prevalence of prescribing errors

A total of 6237 newly written medication orders were studied across three organisations and 10 wards; 368 erroneous prescribing omissions were also identified, giving a denominator of 6605. These data relate to 1289 drug chart screenings (since the same patient's drug chart may be screened by a pharmacist more than once on successive days) and an estimated 1771 patient days. For 493 (38.2\%) of 1289 drug chart screenings, the pharmacist also checked the patient's medication history at the same time.

Overall, 1025 prescribing errors were identified in 974 of 6605 medication orders $(14.7 \%, 95 \%$ CI $13.8 \%$ to $15.6 \%)$. This corresponds to 58 prescribing errors per 100 patient days.

\section{Types of prescribing error}

The types of error are summarised in figure 1 . The three most common errors were omission of medication that was clinically indicated, incorrect dose and incomplete prescription.

In the sample, there were three types of medication orders: regular $(n=4700)$, 'when required' $(n=1237)$ and discharge medication $(n=668)$. The proportions of each were similar across the three organisations. When expressed by medication order type, the error rate associated with discharge medication $(9.0 \%$, $95 \%$ CI $6.8 \%$ to $11.2 \%$ ) was lower than the error rate for the other types (15.3\% of regular medication orders, $95 \%$ CI $14.3 \%$ to $16.3 \%$, and $15.2 \%$ of 'when required' orders, $95 \%$ CI $13.2 \%$ to $17.3 \%)$.

For the 4035 medication orders that were screened by the pharmacist at the same time as checking the patient's medication history, the error rate was $17.3 \%$; for the other 2564 medication orders, the error rate was lower at $12.1 \%$ ( $95 \%$ CI for the difference $3.5 \%$ to $6.9 \%$ ).

\section{Rectification of errors}

Pharmacists recorded the number of doses given (or omitted) before the error was corrected for 904 (88.2\%) of 1025 errors. A mean of 0.9 doses were given (or omitted) before the error was corrected (range 0-11). In $522(57.7 \%)$ cases, the error was corrected before any doses were administered. In the remaining 382 cases where at least one dose was given before correction, a mean of 2.0 doses were administered. Overall, $69.4 \%$ of errors resulted in a pharmacist's intervention to correct the error. In general, those cases for which no interventions were made were those where minor amendments or clarifications could be made by the pharmacist without reference to a prescriber.

\section{Comparison between specialties, wards and organisations}

The error rate identified for the medical admissions wards was significantly higher than the error rate on the surgical wards (table 2; $95 \%$ CI for the difference $2.4 \%$ to $5.8 \%$ ), due to a difference in the prevalence of omission errors (figure 1). These largely related to the omission of patients' usual medication following admission to hospital; a high proportion of prescribing on admissions wards relates to prescribing patients' usual medication following emergency admission. Errors were generally identified earlier on the medical admissions wards than on the surgical wards and were more likely to result in a pharmacist's intervention (table 2).

The prevalence of erroneous orders identified was significantly higher at organisation $\mathrm{C}$ than at organisations $\mathrm{A}$ and $\mathrm{B}$ (CIs presented in table 2). Prescribing errors at organisation $\mathrm{C}$ were less likely to result in pharmacists' interventions, and more doses were given before they were corrected. There was a lower rate of omission errors and a higher rate of dose errors at organisation $B$ in comparison with the other two organisations (figure 2).

There was no clear evidence of any impact of the pre-printing of units on the drug chart at organisation C; there were three errors in organisation A that may have been prevented by such pre-printed units and one error in organisation $C$ that was likely to have been caused by the pre-printed units. However, the lack of a section for the maximum dose or frequency in the "when required' section of organisation B's drug chart appears to have increased errors involving failure to specify the maximum dose of 'when required' medication; there was 1 error of this type at organisation A (2.6\% of all 'when required' orders), 35 at organisation B (45.5\%) and 10 at organisation C (14.9\%). The difference is statistically significant $\left(p<0.001 ; \chi^{2}\right.$ test).

Logistic regression analysis showed that after taking into account the impact of whether or not a medication history had been taken for the patient at the time of pharmacist screening, there was no significant effect for specialty $(p=0.1)$. Specialty was therefore dropped from the multi-level model, where we
Figure 1 Prevalence of different categories of prescribing error by clinical specialty.

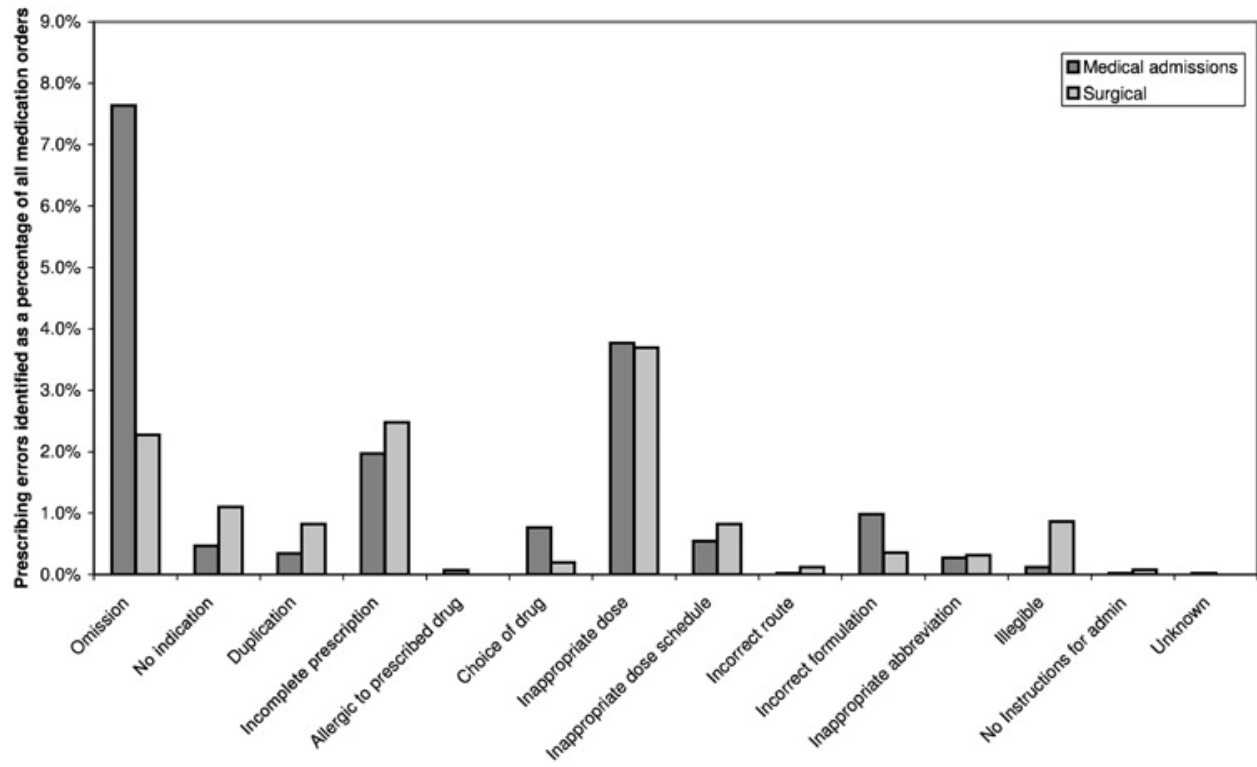


Table 2 Prevalence of erroneous orders and action taken to remedy them, by clinical specialty and organisation

\begin{tabular}{|c|c|c|c|c|c|c|}
\hline $\begin{array}{l}\text { Organisation/ } \\
\text { specialty }\end{array}$ & $\begin{array}{l}\text { Number of } \\
\text { medication } \\
\text { orders screened }\end{array}$ & $\begin{array}{l}\text { Incidence of erroneous } \\
\text { medication orders } \\
(95 \% \mathrm{CI})\end{array}$ & $\begin{array}{l}\text { Errors identified } \\
\text { per } 100 \text { patient } \\
\text { days }\end{array}$ & $\begin{array}{l}\text { Percentage of } \\
\text { errors that resulted } \\
\text { in an intervention }\end{array}$ & $\begin{array}{l}\text { Number of errors for } \\
\text { which the number of } \\
\text { doses given was recorded }\end{array}$ & $\begin{array}{l}\text { Mean number of doses } \\
\text { given or omitted before } \\
\text { error corrected }\end{array}$ \\
\hline Medical admissions & 4059 & $16.3 \%(15.2 \%$ to $17.4 \%)$ & 80 & $76.4 \%$ & $601(87.0 \%)$ & 0.5 \\
\hline Total & 6605 & $14.7 \%(13.8 \%$ to $15.6 \%)$ & 58 & $69.4 \%$ & $904(88.2 \%)$ & 0.9 \\
\hline A & 2689 & $13.6 \%(12.3 \%$ to $14.9 \%)$ & 53 & $70.1 \%$ & $333(86.7 \%)$ & 0.6 \\
\hline B & 1812 & $12.2 \%(10.7 \%$ to $13.7 \%)$ & 47 & $74.5 \%$ & $207(89.6 \%)$ & 0.8 \\
\hline
\end{tabular}

found that, as well as, whether or not a medication history had been taken for the patient at the time of pharmacist screening $(p<0.001)$, there were also significant sources of variation between wards (nested within organisation; $p=0.01$ ) and organisations $(p<0.001)$.

\section{Clinical importance}

We assessed clinical importance of 183 prescribing errors, which had a mean score of 5.3 with little variation between organisations (mean scores: organisation A, 5.2; organisation B, 5.5; organisation C, 5.4) or specialties (admissions, 5.4; surgical, 5.4). A total of 34 (19\%) errors were classed as serious; examples are given in table 3 . Errors associated with pharmacists' interventions had a mean score of 5.5 ; those without interventions had a mean score of 4.8 .

\section{Causes of prescribing errors}

Fifteen interviews were conducted (three pharmacists, a nurse and a locum doctor from organisation A; two pharmacists, a consultant and a junior doctor from organisation $\mathrm{B}$; and two pharmacists, two nurses and two junior doctors from organisation $\mathrm{C}$ ).

\section{Organisation and management factors}

These included the training of junior medical staff both at medical school and within hospitals:

They don't pay attention to these things in medical school so I think this goes very deep where awareness and attitude from medical school has to change. (Pharmacist 3, organisation A)

The lack of a common information system between primary and secondary care was also identified:
It's Chinese whispers, isn't it? I get given a list of drugs from the GP or from the ambulance man who's copied it down from the daughter, he gives it to me and then I copy it down. And then the nurses give it and then we change it and I write it down, then I write a letter to the GP and then that letter gets back to the GP ... (Doctor 3, organisation C)

But obviously if they're at a loss as to whether somebody takes [levo] thyroxine every day, or takes iron tablets .... It might be that hopefully we might be lucky and a patient might come in with their relatives and we can quiz them. (Nurse 4 , organisation A)

\section{Work environment}

These factors included insufficient or inexperienced staff, workload and time pressures and distractions while prescribing:

Just pressure of time is the main one that just makes you potentially make mistakes. Not having time to, if a patient's got polypharmacy and you've been asked, for example, to treat heart failure so potentially you're starting three or four drugs, diuretics, ACE inhibitor, didge [digoxin], a rate control agent, for each of those drugs there are meant to be certain criteria, maybe I haven't always checked the renal function before I start an ACE inhibitor for example, because I'm in a rush. (Doctor 3, organisation C)

Additionally, doctors described how, during overnight shifts, prescribing for patients they were not familiar with could contribute to error:

Sometimes you just don't have enough time or you don't really know the patient, if you're on nights or late and you're covering the whole hospital and you don't know the patient and you don't know that much about them and you're suddenly asked to, can you prescribe this? (Doctor 4, organisation B)
Figure 2 Prevalence of different categories of prescribing error in each study organisation.

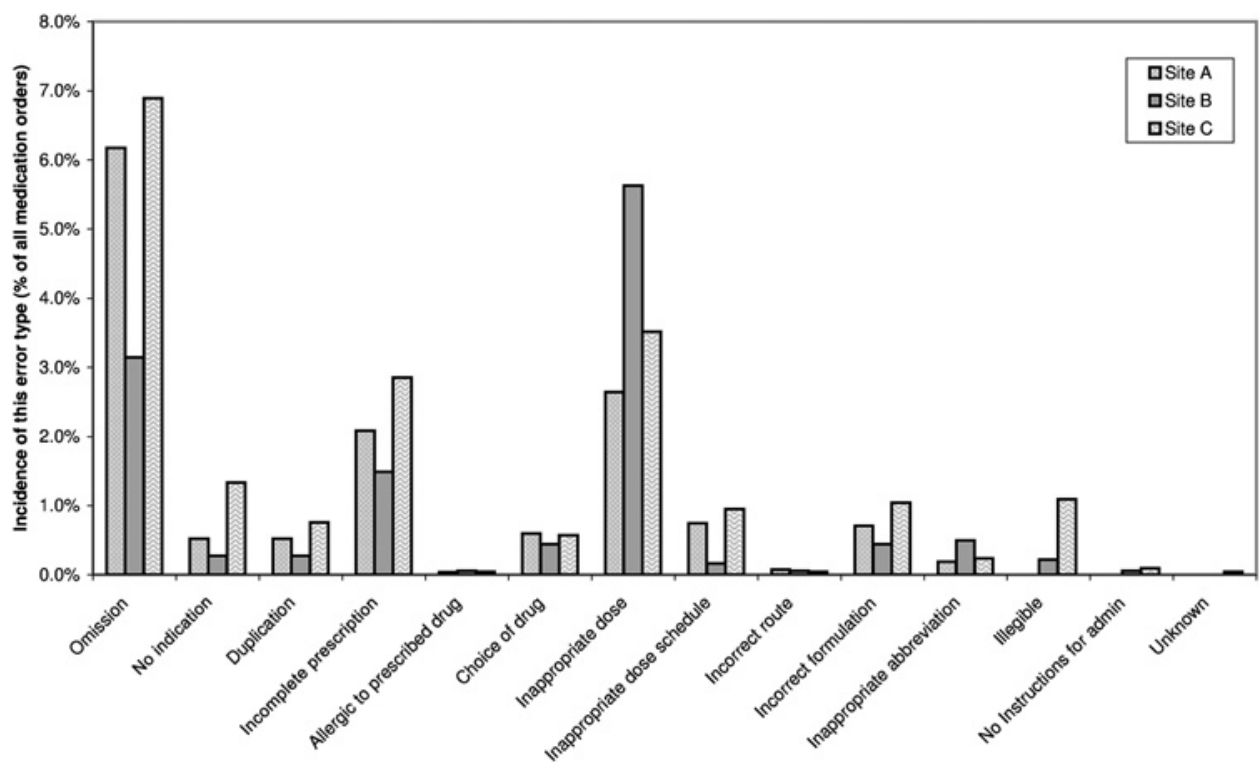


Table 3 Examples of prescribing errors classed as 'serious'

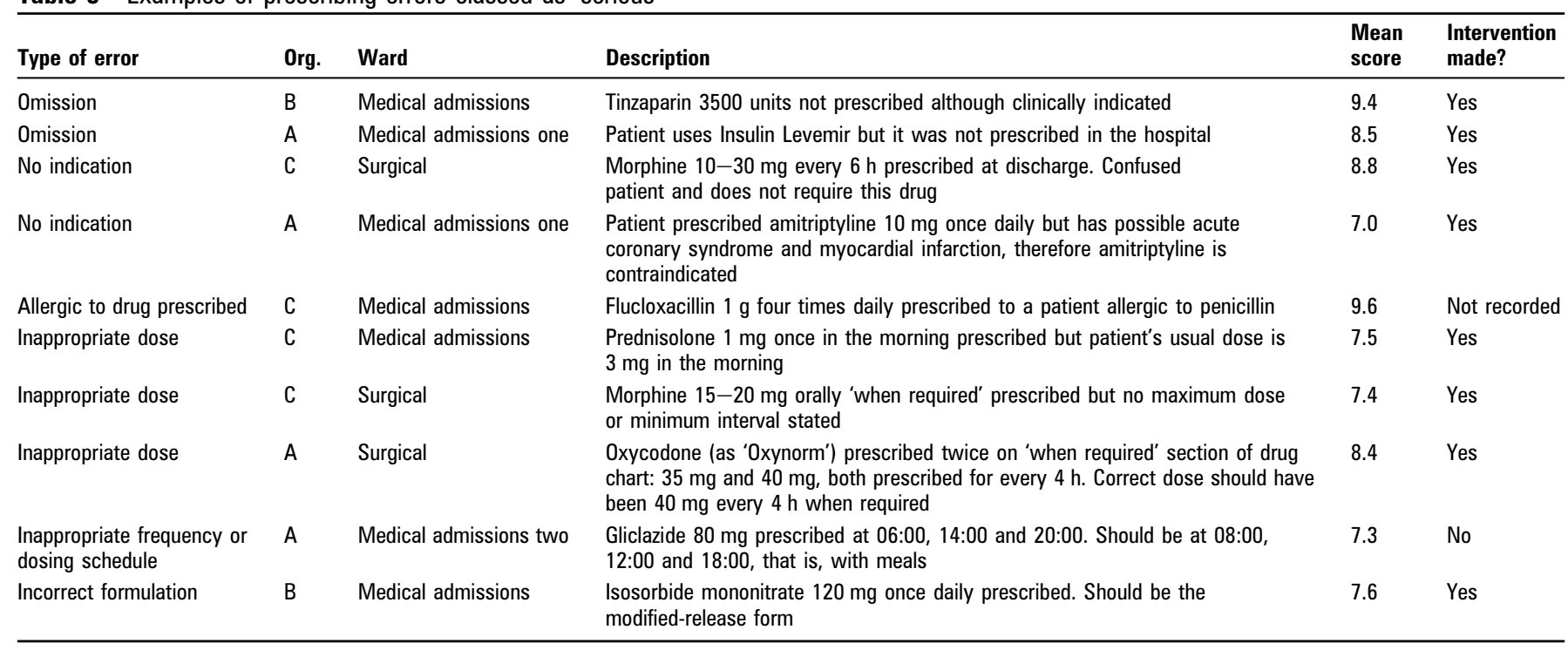

'Outlier' patients on distant wards were described as adding stress and time pressures.

\section{Team factors}

These included incomplete supervision and poor written communication:

Well, they [consultants] come on the ward rounds, and they do give them [junior doctors] a general, they'll say, stop the ... tablet or whatever, and change it to this, or we'll give them bisoprolol instead of whatever... but then once they've gone, they've finished their ward round and they're gone, generally the doc, the junior doctors are left on their own to muddle through. (Nurse 2, organisation C)

My issue with prescribing communication is that in hospital settings it's not clearly documented in the medical notes... It doesn't get written in the notes, the patient gets transferred, nobody knows, the patient continues on the medicine even if it's not working, ultimately it gives them side effects and makes them fall. (Pharmacist 3, organisation A)

... they might have doses from another, an old drug chart, for example, or a drug name from an old drug chart where they, someone's written it and because they're not familiar with the drug they'll write what they think they can see so, and it's not correct, so they write something that looks incorrect or might look like something else or looks like no drug. (Pharmacist 1, organisation A)

Professional hierarchy resulted in reluctance on the part of junior staff to question their seniors, perhaps due to lack of confidence or reluctance to exhibit a lack of knowledge:

I think sometimes junior doctors don't like to question what the consultant says, so if the consultant says, prescribe this drug, or, prescribe this dose, the junior doctor thinks that doesn't sound right but they do it anyway. (Pharmacist 5 , organisation $\mathrm{C}$ )

There was some suggestion of over-reliance on pharmacists and nurses to identify and correct prescribing errors:

We've got two safety nets, the nurses are the first one and the pharmacists are the second one. And nothing gets prescribed from the pharmacy unless everything is fine with the drug chart. If we send the drug chart down to pharmacy and it's wrong, they'll just send it back, but they check it. (Doctor 3, organisation C)

It's been known where they just leave the dose blank intentionally because they know a pharmacist will come along and check it or question them or write something in or sort it out, which they probably shouldn't be doing. (Pharmacist 1, organisation A)

Lack of feedback to prescribers was often highlighted. This was partly because if one doctor makes an error, a different doctor will often rectify it, and partly because pharmacists often correct minor or obvious errors on the drug chart without informing the prescriber:

And there's another key issue here as well especially if you're in an area where there's a lot of doctors rotating, sometimes that phenytoin prescription is written by Doctor $\mathrm{X}$, Doctor $\mathrm{X}$ has gone home so I have to go to Doctor $Y$ and get them to change it and that's fine, they learn something new, but Doctor $\mathrm{X}$ who wrote the prescription doesn't know anything about it. (Pharmacist 3 , organisation A)

Also for something like aspirin, I know most pharmacists would just add that on to the drug chart and PNC [prescriber not contacted], so not contact the prescriber because it's so small you wouldn't contact the doctor just to say, oh it should be enteric coated or, oh it should be dispersible and you didn't write that on....A lot of the time we'll change, we'll add modified release and, without probably telling the doctor. (Pharmacist 1, organisation A)

\section{Task-related factors}

These included prescribing guidelines, availability of clinical information out of hours, drug chart design, lack of standardisation and lack of familiarity with certain drugs or tasks:

Why we don't put maximum doses? It's going to sound silly, probably because there's not a box for it, and if you're writing something like paracetamol or something or maybe even tramadol that you write a lot, you just know it and it's just more the routine, but if there's a little box saying maximum dose, because you normally just, you kind of just put, blah, blah, blah PRN, this amount and then it's just, and then you sign it ... (Doctor 4, organisation B)

Lack of standardisation in prescribing certain drugs was perceived to be a problem, for example, in prescribing drugs that were given less often that once weekly or those that were to be stopped at a future date:

... everyone's got different ways of writing, give for three days and stop, and some people just write three days and assume that the nurse won't give it on the fourth day, and some people will colour 
in the days they want it to give and then make crosses and it's obvious that it stops. (Doctor 3, organisation C)

\section{Defences}

The main defence identified by most interviewees was the pharmacist, particularly when available on ward rounds:

Yeah, I know [pharmacist X] and [pharmacist Y] and I've gone to see them because I ask them, they're normally on the ward the same time each day and it's common place to take both the pharmacists with us, so quite often, I know them quite well to ask them and say, just check things really, do we normally give this much or? So that's really helpful, we do ask them. (Doctor 4, organisation B)

Nurses were also identified as defences. All three participating organisations had electronic prescribing systems available for discharge prescriptions, and these were viewed positively:

So we've now moved to an electronic discharge system, whereby there can't be any ambiguity with the wording... (Doctor 4, organisation C)

There was an assumption that inpatient electronic prescribing and an electronic national care record would reduce prescribing errors:

Well I guess that ultimately you'd have complete electronic systems wouldn't you? The GP, and a national system that you could tap into at any time of day. And anything, any medication that was changed would be entered onto that, but at present I think that's a bit of a dream rather than a reality. (Pharmacist 6, organisation C)

Interviewees, however, were also aware of their limitations:

The things that the computers wouldn't help with would be things like missing things off drug histories and the computer's not going to know if you've not even attempted to put it in there.

(Pharmacist 2, organisation A)

It's not the only solution because you can still make mistakes. You just make a different sort of mistake. (Pharmacist 1, organisation B)

\section{DISCUSSION}

\section{Key findings and interpretation}

We identified prescribing errors in $14.7 \%$ of newly written medication orders and serious errors in $2.8 \%$. There were significant differences between wards, organisations and clinical specialties, although differences between the two clinical specialties were likely to have been accounted for by differences in the proportion of prescribing taking place immediately following admission, when omission of patients' medication was commonly identified.

The lack of information from primary care about patients' medication was cited as a factor contributing to error in the interviews, as recognised by the NICE/NPSA recommendation that pharmacy staff are involved in medication reconciliation as soon as possible after patient admission. ${ }^{22}$ Other factors contributing to prescribing errors included drug chart design, exemplified in one organisation with errors occurring due to the lack of a section to specify the maximum dose or frequency for "when required' medication. A lack of standardisation in how certain drugs are prescribed and poor documentation of prescribing decisions were also considered to contribute to prescribing errors.

A mean of 0.9 doses were administered (or omitted) before each error was corrected. Again, there were significant differences between specialties and organisations in this respect, most likely due to differences in the pharmacy services provided.

\section{Comparison with the literature}

Our error rate of $14.7 \%$ is higher than in most published studies. $^{2}$ However, there are many subtle methodological differences between studies of prescribing errors. ${ }^{7}$ Studies using comparable methodology report a median error rate of $9.9 \%$ (range $7.7-14.6 \%)^{7}$ and a UK study presenting error rates according to different clinical specialties ${ }^{15}$ presents higher rates for two specialties with high patient turnover, comparable with the medical admissions units included in our study. Our findings are also in line with a recent UK study ${ }^{23}$ which found that errors were more likely at admission than at other times, independent of ward type. Our findings in relation to the causes of errors are similar to those in previous UK studies, ${ }^{19} 202425$ but specific issues were also identified in relation to drug chart design.

\section{Strengths and limitations}

A strength of this study is that we used robust methods and definitions to study prescribing errors on comparable wards in three NHS organisations. This is therefore the first UK study to present comparable data on error rates across organisations in an adult setting, together with exploration of their causes. This is also the first study to present figures on the number of doses administered before errors were corrected. This may be a useful indicator for how good the system's defences are, and we recommend that future studies include this measure. In common with most literature in this area, our data rely on data collection by ward pharmacists, which is likely to be subject to some under-reporting. ${ }^{6}{ }^{23}$ Additionally, comparison between organisations may be affected by confounding factors such as differences in procedures and individual prescribers' practice. Finally, we conducted a relatively small number of interviews. Further work would be needed to explore the generalisability of our findings to other specialties and other NHS organisations, but the broadly similar findings across specialties and organisations would support a reasonable level of generalisability.

\section{Recommendations}

Improved methods are needed to transfer patients' medication histories between primary and secondary care. Longer term strategies include facilitating the development of common electronic information systems between primary and secondary care. In the interim, local initiatives should encourage patients to carry up-to-date records of their medication.

To prevent errors from occurring, we would recommend studies to develop and evaluate educational strategies, formal provision of feedback on prescribing errors and increased use of electronic prescribing in the hospital setting. More research is also needed into the effect on prescribing errors of using nonmedical independent prescribers, such as pharmacists. We need to understand both whether these practitioners make more, less or different errors to those of medical prescribers and also whether there is any subsequent effect on errors made by medical practitioners due to deskilling. Some clarification of roles and responsibilities may be needed for medication history taking following patient admission. Currently, pharmacists provide a key role in this area, potentially leading to medical staff omitting to perform this task. Finally, drug charts in some organisations may benefit from minor changes to design out certain types of error.

To stop errors from causing patient harm, pharmacy services should facilitate more proactive use of pharmacists to provide advice at the point of prescribing or as soon as possible afterwards, rather than retrospectively. 


\section{Main messages}

- This is the first UK study to compare prescribing errors for hospitalised adults across more than one organisation and the first to record the number of erroneous doses given (or omitted) before errors were rectified.

- We found $14.7 \%$ of orders to be erroneous; the most common types of errors were omission, wrong dose and incomplete prescription. A mean of 0.9 doses were administered (or omitted) before each error was corrected (range 0-11).

- There were variations among wards, organisations and specialties in error rates and how quickly they were rectified.

- Exploring reasons for differences between organisations may be useful in identifying best practice and potential solutions.

\section{Current research questions}

- Which interventions are effective in reducing prescribing errors in hospital inpatients?

- How should pharmacy services best be delivered in order to maximise impact on patient safety?

- What is the impact on prescribing errors of increased prescribing by non-medical independent prescribers?

\section{Key references}

- Dean B, Barber N, Schachter M. What is a prescribing error? Qual Health Care 2000;9:232-7.

- Dean B, Schachter M, Vincent C, et al. Causes of prescribing errors in hospital inpatients: a prospective study. Lancet 2002;359:1373-8.

- Franklin BD, Vincent C, Schachter M, et al. The incidence of prescribing errors in hospital inpatients - an overview of the research methods. Drug Saf 2005;28:891-900.

- Lewis PJ, Dornan T, Taylor D, et al. Prevalence, incidence and nature of prescribing errors in hospital inpatients: a systematic review. Drug Saf 2009;32:379-89.

- Tully MP, Ashcroft DM, Dornan T, et al. The causes of and factors associated with prescribing errors in hospital inpatients: a systematic review. Drug Saf 2009;32:819-36.

For all of the above recommendations, work is needed to formally evaluate their benefits, as well as their costs.

\section{CONCLUSION}

This is the first UK study to have compared prescribing errors for hospitalised adults across more than one organisation and the first to document the number of doses given before errors were rectified. There were variations in the prevalence and types of prescribing error among the three organisations, as well as how quickly they were rectified. Exploring reasons for differences between organisations may be useful in identifying best practice and potential solutions.

Acknowledgements We thank Emmanuelle Savarit for conducting interviews and assisting with their analysis and Alex Bottle for assistance with statistical analysis.
We also acknowledge the contributions of all participating ward pharmacists, clinical pharmacy managers and interviewees.

Funding Material used in this paper is based on a Research Report commissioned in 2009 by the Health Foundation (registered charity number 286987). Available at http://www.health.org.uk/publications/evidence-in-brief-how-safe-are-clinical-systems (accessed 31 Mar 2011). Other funders: Health Foundation, NIHR.

\section{Competing interests None.}

Ethics approval This study was conducted with the approval of the Hammersmith and Queen Charlotte's \& Chelsea Research Ethics Committee, reference number 09/H0707/27.

Provenance and peer review Not commissioned; externally peer reviewed.

\section{REFERENCES}

1. Vincent C, Barber N, Franklin BD, et al. The Contribution of Pharmacy to Making Britain a Safer Place to Take Medicines. London: Royal Pharmaceutical Society of Great Britain, 2009

2. Lewis PJ, Dornan T, Taylor D, et al. Prevalence, incidence and nature of prescribing errors in hospital inpatients: a systematic review. Drug Saf 2009;32:379-89.

3. Barber $\mathbf{N}$, Dean B. The incidence of medication errors and how to reduce them. Clin Risk 1998;4:103-6

4. Neale G, Woloshynowych M, Vincent C. Exploring the causes of adverse events in NHS hospital practice. J $R$ Soc Med 2001;94:322-30.

5. Franklin BD, Vincent C, Schachter M, et al. The incidence of prescribing errors in hospital inpatients: an overview of the research methods. Drug Saf 2005; 28:891-900.

6. Franklin BD, Birch S, Savage I, et al. Methodological variability in detecting prescribing errors and consequences for the evaluation of interventions. Pharmacoepidemiol Drug Saf 2009;18:992-9.

7. Franklin BD, McLeod M, Barber N. Comment on prevalence, incidence and nature of prescribing errors in hospital inpatients: a systematic review. Drug Saf 2010;33:163-5 [letter].

8. Ferner RE. The epidemiology of medication errors: the methodological difficulties. $\mathrm{Br}$ J Clin Pharmacol 2009:67:614-20.

9. Ghaleb MA, Barber N, Franklin BD, et al. The incidence and nature of prescribing and medication administration errors in paediatric inpatients. Arch Dis Child 2010;95:115-18.

10. Brock TP, Franklin BD. Differences in pharmacy terminology and practice between the United Kingdom and the United States. Am J Health Syst Pharm 2007; 64:1541-6

11. Dean B, Barber N, Schachter M. What is a prescribing error? Qual Health Care 2000;9:232-7.

12. Ross S, Bond $\mathrm{C}$, Rothnie $\mathrm{H}$, et al. What is the scale of prescribing errors committed by junior doctors? A systematic review. Br J Clin Pharmacol 2009;67:629-40.

13. Department of Health. Building a Safer NHS for Patients: Improving Medication Safety. London: Department of Health, 2004.

14. Donyai $\mathbf{P}, \mathrm{O}^{\prime} \mathrm{Grady} \mathrm{K}$, Jacklin A, et al. The effects of electronic prescribing on the quality of prescribing. Br J Clin Pharmacol 2007;15:133-9.

15. Franklin BD, O'Grady K, Paschalides C, et al. Providing feedback to hospital doctors about prescribing errors: a pilot study. Pharm World Sci 2007;29:213-20.

16. Allan EL, Barker KN. Fundamentals of medication error research. Am J Hosp Pharm 1990:47:555-71.

17. Dean BS, Barber ND. A validated, reliable method for scoring the severity of medication errors. Am J Health Syst Pharm 1999:56:57-62.

18. Kollo A, Dean B. The development of a method to assess the severity of prescribing errors and the effect of related pharmacists' interventions. Abstract Presented at the Sixth Heath Services Research and Pharmacy Practice Conference. Aberdeen. 2000.

19. Dean B, Schachter M, Vincent C, et al. Causes of prescribing errors in hospital inpatients: a prospective study. Lancet 2002;359:1373-8.

20. Sangera IS, Franklin BD, Dhillon S. The attitudes and beliefs of healthcare professionals on the causes and reporting of medication errors in a UK Intensive care unit. Anaesthesia 2007:62:53-61.

21. Vincent C, Taylor-Adams S, Stanhope N. Framework for analysing risk and safety in clinical medicine. BMJ 1998;316:1154-7.

22. NICE/NPSA. Technical Patient Safety Solutions for Medicines Reconciliation on Admission of Adults to Hospital. London: NICE, 2007.

23. Tully MP, Buchan IE. Prescribing errors during hospital inpatient care: factors influencing identification by pharmacists. Pharm World Sci 2009:31:682-8.

24. Dornan T, Ashcroft D, Heathfield H, et al. An in Depth Investigation into Causes of Prescribing Errors by Foundation Trainees in Relation to their Medical Education. EOUIP Study. A Report to the General Medical Council, 2009. http://www.gmc-uk. org/FINAL_Report_prevalence_and_causes_of_prescribing_errors.pdf_28935150. pdf (accessed 1 Jul 2011).

25. Tully MP, Ashcroft DM, Dornan T, et al. The causes of and factors associated with prescribing errors in hospital inpatients: a systematic review. Drug Saf 2009;32:819-36. 